\title{
Conservation policies informed by food system feedbacks can avoid unintended consequences
}

\author{
Staci A. Lewis ${ }^{1,2}$, Carlo Fezzi ${ }^{2,3,4}$, Rachel Dacks ${ }^{5}$, Silvia Ferrini ${ }^{6}$, Philip A.S. James ${ }^{7}$, Lincy Marino $^{8}$, \\ Yimnang Golbuu ${ }^{8}$, Kirsten L.L. Oleson ${ }^{2}$
}

\begin{abstract}
Understanding the feedbacks between food systems and conservation policies can help avoid unintended environmental consequences. Using a survey-based choice experiment and economic modeling, we quantify the potential impact of tourists' responses to a shift in offshore fish supply after the designation of a large-scale marine protected area in Palau. We find that this conservation policy may increase offshore fish prices and tourists' consumption of reef fish, thereby further endangering local reef ecosystems. However, if tourists are offered a sustainable offshore choice, their demand for fish could be kept at current levels, and environmental impacts from increased reef fish consumption would be avoided.
\end{abstract}

\section{Main}

Anticipating and avoiding unintended environmental consequences of conservation policies require careful consideration of both ecological and socio-economic effects. Without such understanding, efforts to promote conservation goals may generate fewer positive outcomes than expected or, in extreme cases, even lead to negative consequences ${ }^{1-4}$. For example, limiting resource access can shift market supply and demand, leading to price changes and consumption of substitute goods. In one illustrative case, when Pacific Northwest logging was curtailed on public land to preserve forest habitats, timber production on private properties increased around the region, significantly reducing the effectiveness of the policy ${ }^{1}$.

17 Negative environmental consequences of conservation policies can manifest through food 18 systems $^{5,6}$. For example, instituting marine protected areas (MPAs $)^{7,8}$ and allocating land to conservation ${ }^{6}$ can generate food security concerns in a situation of resource competition with food production. Food systems can, in turn, generate feedbacks that may cause negative environmental consequences, such as poor fish supply increasing bushmeat demand ${ }^{9}$, although these are less documented ${ }^{9-11}$. To predict and, most importantly, avoid such unintended consequences, it is critical to understand the behavioral incentives created by conservation policies for affected local populations and for tourists. In this respect, tourists' food consumption behavior is often ignored in conservation policy design, even though it is an important driver of food systems, especially in developing nations ${ }^{12}$.

27 Here, we quantify the unintended ecological consequences of conservation policies being 28 generated by tourism via food system feedbacks. In particular, we empirically investigate potential 
unintended environmental impacts on coral reefs ecosystems generated by tourists' behavioral responses to a shift in offshore fish supply after a protected area designation. Rather than simply documenting negative consequences of conservation ex post, this research illustrates how unintended environmental impacts can be anticipated and avoided through assessing socioeconomic behavior before a policy is implemented.

Our empirical analysis focuses on the new, offshore Large-Scale Marine Protected Area (LSMPA) of Palau. During the last decade, several island nations across the world designated policies for safeguarding coastal and marine areas ${ }^{13}$, with LSMPAs now being introduced in the Atlantic, Pacific, and Indian Oceans $s^{14,15}$. Scholars have begun to examine ecological and socioeconomic dimensions of LSMPAs ${ }^{2,16-18}$ but empirical investigations of their potential unintended consequences, which assess feedback impacts from food systems and, at the same time, presents financially-viable solutions, are still lacking. Since 2001, Palau has been attracting over 100,000 visitors per year, which corresponds to five times the resident population. On January 1 , 2020, it fully implemented the sixth largest LSMPA in the world - the Palau National Marine Sanctuary (PNMS). The PNMS legislation bans fishing and all extractive activities in $80 \%$ $\left(500,000 \mathrm{~km}^{2}\right)$ of Palau's offshore Exclusive Economic Zone (EEZ), and limits industrial fishing to only $18 \%\left(114,000 \mathrm{~km}^{2}\right)$ of the remaining EEZ, the residual coastal area being available to reef and coastal fishers. One goal of the PNMS is to grow Palau's nascent domestic offshore fishery, which currently consists of a small fleet of day-boat vessels, with the ultimate intent of reducing pressure on their overexploited reef fish species ${ }^{19,20}$.

The first step of our approach was to identify the potential socio-economic effects of conservation policies on Palau's food systems. PNMS restrictions on industrial fishing are highly likely to significantly reduce offshore fish landings for its domestic market, which, prior to the PNMS, was dominated by foreign, industrial fleets. Such fish include tuna, wahoo, and mahi mahi, which are the main ingredients of tourists' meals in Palau ${ }^{21}$. Any shortage in offshore fish supply is expected to drive up offshore fish-based meal prices, which, in turn, may encourage tourists to increase their reef-fish consumption, intensifying pressure on local reefs. In fact, after only a couple of months since the implementation of the PNMS, supply shortages and subsequent price increases of offshore fish are already leading to increased reef-fish demand from grocery stores and restaurants ${ }^{22}$. This is noteworthy since reef fishes are the chief source of protein for the local population ${ }^{21}$ and support healthy coral reefs - the main attraction drawing tourists to Palau ${ }^{23,24}$. Therefore, the PNMS has the serious likelihood of generating unintended ecological consequences by depleting critical nearshore ecosystems.

The second step was to quantify ex ante tourists' behavioral responses to food supply shortages by investigating their preferences for fish-based and non-fish-based meals (see Methods). We ran tablet-based surveys to assess tourists' fish consumption and, via a choice experiment, their meal preferences. Our results have shown that in 2017 tourists ate $\sim 2$ million meals a year and that $\sim 26 \%$ of these meals included fish, divided roughly equally between reef and offshore (Supplementary Table 7). Furthermore, our choice experiment has indicated that tourists' demand functions for both offshore and reef fish are elastic and characterized by strong substitution effects. Figure 1 shows changes in fish consumption following an increase in the price of offshore 
fish; about $80 \%$ of the drop in offshore-fish meals that follows a price increase is compensated by an increase in reef-fish meals, and other types of food (i.e., non-fish meals) comprise the other $20 \%$. Based on the number of tourists in 2017 , a US $\$ 10$ increase in offshore-fish meal prices would generate a drop of 52,000 offshore-fish meals per year consumed by tourists and a simultaneous increase of more than 40,000 reef-fish meals. The trend persists as price increases, implying that demand for reef fish could escalate further if the price of offshore-fish meals balloons. In this representation, we assumed the price of reef fish to remain constant, although it is possible that, in the long run, reef-fish price will also increase due to higher demand levels (we explore the implication of such demand cross-elasticities in SI.8). Still, the feedback effect of food systems from the PNMS policies poses a concrete risk of increasing human pressure on Palau's vital reef ecosystems ${ }^{23}$.

Figure 1 - Insert here

While our demand analysis shows that socio-economic effects via food systems could lead to unintended environmental degradation, it also reveals that harnessing tourists' preferences may provide a solution if the right incentives are provided. In particular, tourists have a significantly higher willingness to pay (WTP) for offshore fish that is marketed as local and sustainable, i.e. sustainably caught by a Palau-based fleet. Similar fishery certifications have been widely used to provide a price premium to sustainable harvesters ${ }^{25}$. Figure 2 (panel a) shows that this WTP is particularly high for middle- and high-income tourists, who are willing to spend an extra US $\$ 15$ for an offshore-fish meal which is locally and sustainably caught (see Supplementary Information). This price premium represents an economic opportunity for local fishers and restaurants; Palau's nascent domestic offshore fishery will require capital investments and capacity building, so capturing this WTP could improve this sector's viability while also curtailing tourists' demand for 92 reef-fish meals.

Alongside this financial opportunity there are also potential environmental effects, since shifts in demand will modify fishing pressure on the reef. To investigate this issue, we simulated the changes in reef and offshore fish consumption if the price of offshore-fish meals increases by US\$10 in two different scenarios: industrial fisheries (IF) and local sustainable fisheries (LSF). As the baseline, we used prices and consumptions before the implementation of the PNMS. As figure 2 (panel b) shows, in the first scenario, offshore fish is caught by foreign-owned IF that do not implement sustainable practices (i.e., current conditions), while in the second one, offshore fish is caught by a Palau-based fleet in a sustainable manner. We simulated changes for all tourists and by income levels. In line with our demand function estimates, the IF scenario showed a significant drop in offshore fish consumption (about $23 \%$, corresponding to the 52,000 meals in Figure 1) and an almost equal increase in reef-fish meals due to the price increase. This effect was consistent across all income groups. On the other hand, in the LSF scenario we observed practically no change overall, with reef and offshore fish consumption remaining roughly the same as in the baseline, despite the price change. However, the lack of overall change in consumption masks the significant difference between income groups. Low-income tourists have low WTP for local sustainable offshore fish and, therefore, switch to reef-fish meals. This effect is compensated by the large change in consumption of middle- and high-income tourists who, despite the higher 
110 price, consume more offshore fish (and less reef fish) because of their high WTP. Results suggest 111 that a local, sustainable brand of offshore fish can bring financial opportunities, particularly if the 112 tourism base is wealthier-Palau's current tourism strategy ${ }^{26}$. Such branding can also create 113 positive externalities by halting the increase in fishing pressure on Palau's reefs that a surge in 114 offshore fish price would otherwise generate. Nevertheless, taking into account heterogeneity in 115 preferences across tourists is important to understand future consumption and environmental 116 impacts, particularly if the proportion of low-income tourists will increase in the future.

Figure 2 - Insert here

117 Conservation policies such as establishing MPAs can attract more tourists (as already seen in 118 Vietnam $^{8}$, for example), yet positive outcomes can co-occur with negative ones. Our study 119 demonstrates that the design of conservation policies should consider and aspire to anticipate 120 food system feedbacks, including the wider implications of tourists' behavioral responses. 121 Policies' indirect socio-economic effects via food systems can cause unintended environmental 122 consequences, but when understood and harnessed in the right direction, they can also offer 123 potential win-win solutions. In the case of Palau, implementing the PNMS alongside a market-

124 based intervention which provides a price premium for verified sustainably- and locally-sourced 125 offshore fish could increase income for local fishers and fish retailers. Consumers are willing to 126 pay a price premium for fish that they know is locally and sustainably caught, but whether a 127 domestic local fishery is able to supply enough fish at this price needs to be investigated. 128 Moreover, credibility will depend on robust monitoring and verification programs to ensure 129 compliance with sustainable practices.

130 Our results, though specific to Palau, are potentially applicable to other nations where tourism 131 strongly drives food system and fish are of dietary and cultural importance. Our approach is 132 broadly generalizable for investigating ex ante the interactions between conversation policies and 133 tourists' behavior, as well as sustainable solutions to mitigate unintended consequences of 134 tourism-driven food systems impacts. As nations seek to meet international protected area 135 agreements and achieve sustainable development goals through large-scale conservation 136 actions, ex ante systematic analyses of socioeconomic trade-offs for food systems and 137 preferences of both locals and tourists are crucial for sound policy.

\section{Methods}

138 Tourist surveys (in English, Korean, Mandarin Chinese, Taiwanese and Japanese) were 139 conducted from August 2017 to January 2018 in Palau. In total, 409 valid tablet-based responses 140 represented the island's tourist demographics (see Supplementary Information). The profile of 141 tourists' current fish consumption was obtained by asking respondents to report the trip duration, 142 number of fish-based meals (i.e., breakfasts, lunches, and/or dinners) consumed in Palau by type 143 (reef, tuna, other non-tuna offshore) and form (whole, cooked fillet, or raw). Results were 144 reweighted in order to match the share of tourists in Palau in 2017 (see Supplementary 145 Information) and to accommodate that $\sim 7 \%$ of our sample reported to not eat fish. As the number 
of fish-eating respondents were not normally distributed across all groups, a sequential hurdle model was run in the $R$ statistical software package "glmmTMB" 27 to test for consumption differences across nationalities (see Supplementary Information).

The discrete choice experiment comprised credible restaurant menus with varying prices, in which respondents had to indicate their preferred meal option, using a decomposition approach ${ }^{28}$. Each menu offered four fish and one non-fish meal, which included both meat and non-meat meals and, in effect, served as the outside option ${ }^{29}$. Fish-eating respondents were presented with a random set of 12 menus. Fish-based meals included the following 11 options: reef fish (whole, fillet, or raw), tuna (raw, cooked, local-sustainable (LS) raw, or LS cooked), and non-tuna offshore fish (raw, cooked, LS raw, or LS cooked). The price of each fish-based meal varied between $\$ 10$ and $\$ 75$ (see Supplementary Information). The menus and prices were produced using a Defficient design.

The analysis of our discrete choice experiment responses follows the random utility model framework ${ }^{30}$. Therefore, tourists' preferences are captured by the following equation:

$$
\bigcup_{i k j}=\alpha_{j}+\beta \text { price }_{i k j}+\varepsilon_{i k j},
$$

where $i$ indicates the respondent, $k=1, . ., 12$ the choice cards and $j$ the choice options. $\varepsilon_{\text {ikj }}$ is the error term. The intercept $\alpha_{\mathrm{j}}$ corresponds to the difference in utility between the non-fish meal and the j-esim fish meal, $\beta$ (which we expect to be negative) indicates the dis-utility of cost. Assuming error terms to be independent, identically distributed Gumbel random variables, the probability of choosing option $\mathrm{j}$ can be written in a conditional logit form and the parameters of equation (1) estimated via maximum likelihood ${ }^{25}$. Within this framework, the WTP is defined as $-\alpha_{i} / \beta$ and its confidence interval can be obtained via the Krinsky and Robb approach ${ }^{31}$. This WTP can be interpreted as the additional amount respondents are willing to pay to order that specific fish dish instead of the non-fish (meat or vegetarian) option.

Finally, the preference parameters estimated in equation (1) can be used to simulate the demand functions for the different types of meals (see Supplementary Information). A debate exists on the extent of hypothetical bias affecting WTP estimates from stated preferences ${ }^{32}$. Recent findings suggest that this bias is likely to be stronger for public goods than for market goods $29,33,34$ and, therefore, our approach should be relatively less affected by this issue. Nevertheless, in the SI.8 we illustrate how our findings would change if the additional WTPs for LS fish meals would be only one half of the values we estimate in our CE.

\section{Data availability}

177 The authors declare that all data supporting the findings of this study are available within the 178 paper and its Supplementary Information and Data files.

\section{Code availability}


179 The custom code generated for this study is in the Supplementary Data file.

\section{References}

1. Polasky, S. Planning with feedback effects. Proc. Natl. Acad. Sci. 103, 5245-5246 (2006).

2. Ban, N. C. et al. Well-being outcomes of marine protected areas. Nat. Sustain. 2, 524532 (2019).

3. Canavire-Bacarreza, G., Diaz-Gutierrez, J. E. \& Hanauer, M. M. Unintended consequences of conservation: Estimating the impact of protected areas on violence in Colombia. J. Environ. Econ. Manage. 89, 46-70 (2018).

4. Grafton, R. Q. et al. The paradox of irrigation efficiency. Science (80-. ). 361, 748-750 (2018).

5. Laudan, J., Hanspach, J., Abson, D., French Collier, N. \& Fischer, J. The intersection of food security and biodiversity conservation: A review. Reg. Environ. Chang. (2015).

6. Garnett, T. et al. Sustainable intensification in agriculture: Premises and policies. Science (80-. ). 341, 33-34 (2013).

7. Balmford, A., Gravestock, P., Hockley, N., McClean, C. J. \& Roberts, C. M. The worldwide costs of marine protected areas. Proc. Natl. Acad. Sci. U. S. A. 101, 96949697 (2004).

8. Ngoc, Q. T. K. Impacts on the ecosystem and human well-being of the marine protected area in Cu Lao Cham, Vietnam. Mar. Policy 90, 174-183 (2018).

9. Brashares, J. S. et al. Bushmeat hunting, wildlife declines, and fish supply in West Africa. Science (80-. ). 306, 1180-1183 (2004).

10. Rentsch, D. \& Damon, A. Prices, poaching, and protein alternatives: An analysis of bushmeat consumption around Serengeti National Park, Tanzania. Ecol. Econ. 91, 1-9 (2013).

11. Inogwabini, B. I. Bushmeat, over-fishing and covariates explaining fish abundance declines in the Central Congo Basin. Environ. Biol. Fishes 97, 787-796 (2014).

12. Degarege, G. A. \& Lovelock, B. Sustainable tourism development and food security in Ethiopia: Policy-making and planning. Tour. Plan. Dev. 16, 142-160 (2019).

13. Wood, L. J., Fish, L., Laughren, J. \& Pauly, D. Assessing progress towards global marine protection targets: Shortfalls in information and action. Oryx 42, 340-351 (2008).

14. Toonen, R. J. et al. One size does not fit all: The emerging frontier in large-scale marine conservation. Mar. Pollut. Bull. 77, 7-10 (2013).

15. Smyth, C. \& Hanich, Q. Large scale marine protected areas: Current status and consideration of socio-economic dimensions. (2019).

16. Gray, N. J. et al. Human dimensions of Large-Scale Marine Protected Areas: Advancing research and practice. Coast. Manag. 45, 407-415 (2017).

17. Lester, S. et al. Biological effects within no-take marine reserves: A global synthesis. Mar. Ecol. Prog. Ser. 384, 33-46 (2009).

18. Gruby, R. L. et al. Policy interactions in large-scale marine protected areas. 1-9 (2020). doi:10.1111/conl.12753

19. Friedlander, A. M. et al. Size, age, and habitat determine effectiveness of Palau's Marine Protected Areas. PLoS One 12, 1-18 (2017).

20. Golbuu, Y. \& Friedlander, A. M. Spatial and temporal characteristics of grouper spawning aggregations in marine protected areas in Palau, western Micronesia. Estuar. Coast. Shelf Sci. 92, 223-231 (2011). 
21. Dacks, R., Lewis, S. A., James, P., Marino, L. L. \& Oleson, K. Documenting baseline value chains of Palau's nearshore and offshore fisheries prior to implementing a largescale marine protected area. Mar. Policy 14, (2020).

22. Carreon, B. Palau's marine sanctuary backfires, leading to increased consumption of reef fish. The Guardian (2020).

23. Birkeland, C. Working with, not against, coral-reef fisheries. Coral Reefs 36, 1-11 (2017).

24. Wabnitz, C. C. C., Cisneros-Montemayor, A. M., Hanich, Q. \& Ota, Y. Ecotourism, climate change and reef fish consumption in Palau: Benefits, trade-offs and adaptation strategies. Mar. Policy 88, 323-332 (2018).

25. Kemmerly, J. D. \& Macfarlane, V. The elements of a consumer-based initiative in contributing to positive environmental change: Monterey Bay Aquarium's seafood watch program. Zoo Biol. 28, 398-411 (2009).

26. Bureau of Tourism, M. Palau responsible tourism policy framework: 2017-2021. (2016).

27. Brooks, M. E. et al. glmmTMB balances speed and flexibility among packages for zeroinflated generalized linear mixed modeling. $R$ Journal 9, 378-400 (2017).

28. Bradburn, N. M., Rips, L. J. \& Shevell, S. K. Answering autobiographical questions: The impact of memory and inference on surveys. Science (80-. ). 236, 157-161 (1987).

29. Johnston, R. J. et al. Contemporary guidance for stated preference studies. J. Assoc. Environ. Resour. Econ. 4, 319-405 (2017).

30. McFadden, D. Conditional logit analysis of qualitative choice behaviour. in Frontiers in Econometrics (ed. Zarembka, P.) (Academic Press, 1973).

31. Krinsky, I. \& Robb, A. On approximating the statistical properties of elasticities. Rev. Econ. Stat. 86, 715-19 (1986).

32. Loomis, J. What's to know about hypothetical bias in stated preference valuation studies? J. Econ. Surv. 25, 363-370 (2011).

33. Hudson, D., Gallardo, R. K. \& Hanson, T. R. A comparison of choice experiments and actual grocery store behavior: An empirical application to seafood products. Journal of Agricultural and Applied Economics 44, 49-62

34. Beck, M. J., Fifer, S. \& Rose, J. M. Can you ever be certain? Reducing hypothetical bias in stated choice experiments via respondent reported choice certainty. Transp. Res. Part B Methodol. 89, 149-167 (2016).

\section{Acknowledgements}

We thank National Geographic Pristine Seas for funding this project; the Palau International Coral Reef Center for coordinating and supporting the data collection; the survey enumerators, including Andrea Uchel and Tarita Holm; Tom Oliver for providing advice on our statistical analysis; the Editor Juliana Gill for her assistance; and the Reviewers for their insightful comments.

\section{Author information}

\section{Affiliations}

1 Stanford University Center for Ocean Solutions, 473 Via Ortega, Room 193, Stanford, CA 94305 USA

2 Department of Natural Resource and Environmental Management, University of Hawaii at Manoa, 1910 East-West Road, Sherman Laboratory 101, Honolulu, HI 96822

3 Department of Economics and Management, University of Trento, via Vigilio Inama 5, Trento, Italy 38122 
4 Land, Environment, Economics and Policy Institute, University of Exeter, Rennes Drive, Exeter, Devon, EX4 4PU UK

5 School of Life Sciences, University of Hawaii at Manoa, 3190 Maile Way, St. John 101, Honolulu, HI 96822

6 University of Siena, Via Mattioli, 53100, Siena (IT) and University of East Anglia, Chancellor Drive, Norwich NR4 7TJ UK

7 Pacific Community (SPC), 95 Promenade Roger Laroque, BP D5, 98848, Noumea, New Caledonia

8 Palau International Coral Reef Center, P.O. Box 7086, 1 M-Dock Road, Koror, PW 96940, Palau

\section{Contributions}

S.A.L., K.L.L.O., and R.D. planned the project. S.A.L., K.L.L.O., R.D., C.F., S.F and P.A.S.J. designed the study. S.A.L. K.L.L.O., R.D. and L.M. collected the surveys. C.F., S.A.L., K.L.L.O., R.D. and S.F. conducted the analysis. C.F. and S.F. designed and estimated the choice experiment analysis. S.A.L., C.F., and K.L.L.O. wrote the paper. R.D., S.F., P.A.S.J., L.M. and Y.G. contributed to the writing.

\section{Corresponding author}

Staci Lewis | e-mail: slewis13@stanford.edu

\section{Ethics declaration}

\section{Competing interests}

The authors declare no competing interests.

\section{Supplementary Information}

Survey Instrument, Supplementary Figures 1 - 5 and Tables 1 - 12

\section{Supplementary Data}

Data and code for respondents' demographics, fish consumption, discrete choice experiment, WTP, and model estimates. 